\title{
Incorporating Near Peers for Teaching and Fast Feedback in a Rapidly Developed Virtual Pediatric Clerkship Curriculum in Response to the COVID Pandemic
}

\author{
Suzanne Friedman ${ }^{1,2}$ (1) Kirsten E. Craddock ${ }^{3} \cdot$ Zachary Pitkowsky $^{3} \cdot$ Marina Catallozzi $^{1,2,3,4}$
}

Accepted: 11 February 2021 / Published online: 23 February 2021

(c) International Association of Medical Science Educators 2021

\begin{abstract}
As COVID-19 necessitated student removal from clinical environments, a virtual curriculum involving existing and novel clerkship elements was developed that utilized near peers for both teaching and feedback. Shelf scores, engagement, and satisfaction demonstrated success of these new curricular elements, many of which will be incorporated for future students.
\end{abstract}

Keywords Neer-peers $\cdot$ Pediatrics $\cdot$ Virtual curriculum

Asynchronous and hybrid learning curricula have been emerging as practical and effective alternatives to traditional learning modalities. However, staffing and logistical challenges have precluded universal uptake. In March 2020, New York City became the epicenter of the COVID pandemic, and medical students were removed from the clinical environment, first in front-line areas and then entirely. As students were in the middle of their Pediatric rotation of their major clinical year, the remainder of the clerkship needed to be revamped and completed remotely. Additionally, given clinical needs, limited faculty were available for engagement in this remote curriculum. This need precipitated the rapid development of a virtual curriculum based in hybrid learning principles and near peer teaching, designed to replace the remaining weeks of the clerkship but with applications for future teaching.

Suzanne Friedman

Sf2723@cumc.columbia.edu

1 Department of Pediatrics, Columbia University Irving Medical Center, 622 W168t St VC 417, New York, NY 10032, USA

2 Morgan Stanley Children's Hospital, NewYork Presbyterian Hospital, New York, NY, USA

3 Vagelos College of Physicians and Surgeons, Columbia University Irving Medical Center, New York, NY, USA

4 Heilbrunn Department of Population and Family Health, Mailman School of Public Health, Columbia University Irving Medical Center, New York, NY, USA
To address the need for curriculum modifications, the clerkship director (CD) and resident as teacher (RAT) curriculum director developed a hybrid learning curriculum using near peers to deliver parts of the curriculum and supplement clinical experiences. Near peers included the “Teach Resident" (TR), a resident on a rotation designed to develop their teaching skills, and the senior medical student liaisons (SMSL), who are two 4th year students facilitating feedback between the clerkship students and CD.

A backward design and student-centered design framework allowed us to center the principles of identifying the desired results for student learning, determine acceptable results and plan learning experiences and instruction accordingly $[1,2]$. In terms of curricular material, a variety of learning modalities and curricular elements were organized into daily themes and adapted for virtual use or newly developed. Teaching tools included virtually adapted existing elements of the clerkship, curated external resources, and novel virtual internal resources. Virtual, asynchronous elements were supplemented with interactive teaching from the TR and SMSLs to enhance learning and skills. Curricular elements were organized into thematic modules for students to complete daily. Modules included high yield pediatric topics including neonatal jaundice, abdominal pain, and the newborn physical exam. Adapted clerkship didactics included virtual interactive lectures, team-based learning over Zoom using breakout rooms (e.g., common infections), and resident conferences and existing outside online pediatric education resources, such as Aquifer asynchronous pediatrics cases, education videos 
Table 1 Student end of clerkship evaluations comparing pandemic-impacted rotation (February 2020) vs prior five rotations (July 2019January 2020) demonstrate no significant difference in rating

\begin{tabular}{llllllll}
\hline & $\begin{array}{l}\text { Learning } \\
\text { objectives }\end{array}$ & $\begin{array}{l}\text { Learning } \\
\text { environment }\end{array}$ & Teaching & $\begin{array}{l}\text { Patient } \\
\text { management }\end{array}$ & $\begin{array}{l}\text { Opportunities } \\
\text { to improve } \\
\text { clinical skill }\end{array}$ & $\begin{array}{l}\text { Overall } \\
\text { clerkship } \\
\text { quality }\end{array}$ & $p$ value \\
\hline $\begin{array}{c}\text { July 2019- } \\
\text { January }\end{array}$ & 3.686 & 3.68 & 3.508 & 3.576 & 3.584 & 3.702 & 0.093569 \\
$\begin{array}{l}2020 \\
(n=84)\end{array}$ & & & & & & & \\
$\begin{array}{l}\text { February } \\
\text { 2020 }\end{array}$ & 3.6 & 3.75 & 3.45 & 3.35 & 3.35 & 3.65 & \\
$(n=20)$ & & & & & & & \\
\hline
\end{tabular}

from OPENPediatrics, and podcasts from Peds Cases. The curriculum also included novel internal resources such as pediatric elements from a residency preparation curriculum for graduating students, local student-developed highyield online learning modules, and additional didactics created by the TR and SMSLs. The TRs taught interactive case-based chalk talks designed to enhance both clinical reasoning and review pediatric pathology. The SMSLs taught via educational gaming and a personalized shelf review session. Additionally, both the TR and SMSLs provided direct feedback to the $\mathrm{CD}$ on the new curriculum and students' experiences to the CD to ensure student wellness, engagement, and satisfaction, further supported by CD-scheduled end-of-day check-in calls with 4 students per day.

To evaluate success of the novel curriculum, student evaluations, NBME shelf exam scores, and videoconference attendance were assessed. Student end of clerkship evaluations across six categories, including those relating to teaching, learning, and overall quality, did not differ significantly between the pandemic-impacted rotation and the prior five rotations (Table 1). The mean score of the NBME shelf exam was within 1 standard deviation of the national mean for quarter 1 . Students remained consistently engaged in the curriculum, with 85 to $90 \%$ of students attending virtual sessions and always communicating when they had to miss. Students remained engaged even after the clerkship ended, attending general and shelf review sessions with the TR, CD, and SMSLs.

Given the positive outcomes of these curricular changes and the ability to continue using virtual resources, some elements of this curriculum will be incorporated into the clerkship going forward to improve access to educational opportunities. The TR had provided near peer education for students on the inpatient portion of their clerkship, and virtual technology can now include outpatient students and those on services or at affiliate hospitals without a TR. The continued use of this hybrid learning expands teaching availability and opportunities, regardless of students' individual clinical encounters. Additionally, the SMSLs and TR, as near peers who are close to the content and level of the students, provided support and directed guidance on high yield educational topics and resources [3, 4]. The use of near peers also distributes teaching hours among multiple training levels, reducing the dependence on faculty [5]. Finally, using the SMSLs and TR as a source of confidential and collective feedback allows for more rapid cycle changes than can be implemented when using rotation evaluations, and this drives further innovation and curricular advancement. Combining self-directed asynchronous and hybrid educational approaches incorporating near peers will serve clinical learners in this new COVID reality.

\section{References}

1. Weimer M. Learner-centered teaching: five key changes to practice. 2nd ed. San Francisco, CA: Jossey-Bass; 2013.

2. Wiggins GMJ. The understanding by design guide to creating highquality units. 2011. https://clio.columbia.edu/catalog/10583234

3. Bene KL, Bergus G. When learners become teachers: a review of peer teaching in medical student education. Fam Med. 2014;46(10):783-7.

4. Lockspeiser TM, O'Sullivan P, Teherani A, Muller J. Understanding the experience of being taught by peers: the value of social and cognitive congruence. Adv Health Sci Educ Theory Pract. 2008;13(3):361-72. https://doi.org/10.1007/s10459-006-9049-8.

5. Geha R, Dhaliwal G. Pilot virtual clerkship curriculum during the COVID-19 pandemic: Podcasts, peers and problem-solving. Med Educ. 2020;54(9):855-6. https://doi.org/10.1111/medu.14246.

Publisher's Note Springer Nature remains neutral with regard to jurisdictional claims in published maps and institutional affiliations. 